\title{
Patient-Reported Benefits of Extracranial Venous Therapy: British Columbia CCSVI Registry
}

\author{
A. Dessa Sadovnick, Irene M. Yee, Kristen Attwell-Pope, Glenn Keyes, Lucas Kipp, \\ Anthony L. Traboulsee
}

\begin{abstract}
Objective: Chronic cerebrospinal venous insufficiency (CCSVI) has been hypothesized to be a risk factor for multiple sclerosis (MS). Venoplasty has been proposed as a treatment for CCSVI. The aim of our study was to gain a better understanding of the "real-world" safety and longitudinal effectiveness of venoplasty Methods: British Columbia residents who self-reported having had venoplasty and consented to participate in the study were interviewed and followed for up to 24 months post-therapy using standardized structured questionnaires Results: Participants reported procedure-related complications (11.5\%) and complications within the first month after the procedure (17.3\%). Initially, more than $40 \%$ of participants perceived that the venoplasty had had positive effects on their health conditions, such as fatigue, numbness, balance, concentration/memory and mobility. However, this improvement was not maintained over time Conclusions: Follow-up patient-reported outcomes indicated that the initial perception of the positive impact of venoplasty on the health conditions of MS patients was not sustained over time. In addition, venoplasty was not without associated morbidity.
\end{abstract}

RÉSUMÉ: Bénéfices rapportés par les patients qui ont subi la thérapie veineuse extracrânienne : le British Columbia CCVI Registry. Objectif : Une hypothèse a été émise selon laquelle l'insuffisance veineuse céphalo-rachidienne chronique serait un facteur de risque de la sclérose en plaques (SP) et la veinoplastie a été proposée comme traitement. Le but de notre étude était de connaître quelle est la sécurité réelle de cette intervention ainsi que son efficacité longitudinale. Méthodologie : Les résidents de la Colombie-Britannique, qui avaient rapporté eux-mêmes avoir subi une veinoplastie et qui ont consenti à participer à l'étude, ont été interviewés et ils ont été suivis au moyen de questionnaires structurés standardisés au cours d'une période allant jusqu'à 24 mois après avoir subi le traitement. Résultats : Des complications reliées à l'intervention ont été rapportées par 11,5\% des participants et des complications au cours du premier mois après avoir subi l'intervention par 17,3\% d'entre eux. Initialement, plus de 40\% des participants considéraient que la veinoplastie avait eu des effets positifs sur leurs problèmes de santé, tels la fatigue, les engourdissements, les problèmes d'équilibre, de concentration/de mémoire et de mobilité. Cependant, cette amélioration n'a pas persisté. Conclusions : Au cours du suivi, les bénéfices rapportés par les patients atteints de SP et la perception initiale de l'impact positif de la veinoplastie sur leurs problèmes de santé ne se sont pas maintenus dans le temps. De plus, la veinoplastie a donné lieu à une certaine morbidité.

Keywords: Multiple sclerosis, chronic cerebral spinal venous insufficiency, CCSVI, venoplasty, patient-reported outcomes, longitudinal study, adverse events

\section{INTRODUCTION}

The aetiology of multiple sclerosis (MS) is unclear, but the important factors include genes, the environment and the interactions thereof. ${ }^{1,2} \mathrm{MS}$ is a demyelinating chronic inflammatory disorder of the central nervous system (CNS), primarily affecting white matter in the brain and spinal cord, and is characterized by myelin loss and axonal pathology. ${ }^{1}$ Approximately 100,000 Canadians have MS, a rate nine times higher than the global average. $^{3}$

In 2009, chronic cerebrospinal venous insufficiency (CCSVI), characterized by stenoses and occlusions in the extracranial veins that drain the CNS, including the internal jugular veins and the azygos veins, ${ }^{4,5}$ was proposed to be important in the pathogenesis of MS. CCSVI, as described by Zamboni et al, ${ }^{6}$ is detectable by transcranial and extracranial Doppler ultrasound. Specific to MS patients, it was reported that the large veins draining blood from the brain and spinal cord appear to be narrowed compared to

From the Department of Medical Genetics, University of British Columbia, Vancouver, British Columbia, Canada (ADS, IMY); Vancouver Island Health Authority, Victoria, British Columbia, Canada (KAP); Wellington Medical Clinic, Nanaimo, British

Columbia, Canada (GK); Department of Medicine (Neurology), University of British Columbia, Vancouver, British Columbia, Canada (ADS, LK, ALT); Department of

Neurology and Neurological Sciences, Stanford University Medical Center, Stanford, California, United States (LK).

Received April 15, 2016. Final Revisions Submitted October 6, 2016. Date of ACCEPTANCE OCTOBER 30, 2016.

Correspondence to: Anthony L. Traboulsee, Department of Medicine (Neurology), UBC Hospital, University of British Columbia, 2211 Wesbrook Mall, Room S113, Vancouver, British Columbia, Canada V6T 2B5. Email: t.traboulsee@ubc.ca. 
people without MS, the hypothesis being that CCSVI causes congestion of blood in the brain and triggers inflammation, possibly by causing iron deposition. ${ }^{7}$ Thus, percutaneous transluminal angioplasty of extracranial veins, a CCSVI treatment termed "liberation therapy" (hereafter referred to as "venoplasty"), was proposed (based on a pilot study with nonrandomized data) as an alternative treatment for MS. ${ }^{8}$ Venoplasty involves the insertion of a catheter with a balloon into the vein with stenosis. The balloon is then inflated to dilate the stenosis. Stenting can be done after dilation.

To date, there is little evidence that venoplasty is an effective MS treatment. A recent review ${ }^{9}$ reported that the majority of studies could not reproduce the initial reports and that venoplasty as a treatment ${ }^{4-8}$ has no proven efficacy, may in fact exacerbate underlying disease activity, and has been complicated with serious adverse events. ${ }^{9}$ Nevertheless, out-of-country venoplasty has continued to attract Canadian MS patients, especially through internet-based resources. ${ }^{10}$

The British Columbia (BC) CCSVI Registry (hereinafter "the Registry"), funded by the BC Ministry of Health, was designed to allow for a better understanding of the "real-world" longitudinal safety and effectiveness of venoplasty as an MS therapy. Our study was approved by the University of British Columbia (UBC) Research Ethics Board, the Vancouver Coastal Health Research Institute (VCHRI) and the Information Privacy Office (VCH IPO).

\section{Materials ANd Methods}

\section{Participants and Data Collection}

Information on the Registry was disseminated through the official VCHRI website, UBC MS clinic visits and its website, multimedia interviews (radio, television, print), and the $\mathrm{BC}$ and Yukon Division newsletter of the MS Society of Canada.

BC residents with MS who self-reported venoplasty were invited to telephone or email the Registry and leave their contact information. They were then contacted in order to explain the study and to invite them to participate. All participants provided informed consent.

Information about venoplasty was obtained from (1) consenting volunteers who had at least one venoplasty and (2) their BC physicians.

While it was anticipated that some participants would have undergone multiple venoplasties for CCSVI, the detailed survey for this study focused only on the venoplasty closest to the initial Registry interview. If multiple procedures occurred during the study period, the subject would be truncated with respect to follow-up at the time of the subsequent procedure(s) and begin again as a new case for the subsequent procedure.

\section{Survey}

"Initial" and "follow-up" questionnaires were administered by telephone. Follow-ups occurred at 6,12 and 24 months after the initial interview.

\section{Survey Content}

Participants were asked about their most recent venoplasty. The survey included questions on the following: (1) mobility assistance prior to and post-treatment; (2) complications during venoplasty and within the first month post-treatment; and
(3) perception of MS-related health conditions (e.g., fatigue, mobility, exercise level, sensory symptoms). The response choices for the patient-reported outcomes were presented as 5-point Likert-type scale items. ${ }^{11}$

Questions on exercise levels were adapted from Ploughman et al.: "light" = easily done physical activity (e.g., light housework); "moderate" = causing slight breathlessness (e.g., yoga, brisk walking); and "vigorous"=causing rapid breathing (e.g., weight training).

As fatigue is one of the most common and most disabling symptoms of MS, ${ }^{13}$ the Modified Fatigue Impact Scale-5 item version (MFIS-5) from the MS Quality of Life Inventory $(\mathrm{MSQLI})^{14}$ was utilized. Scores range from 0 to 20 , with higher scores indicating higher impact of fatigue on participants' activities. A score $<5$ suggests the absence of any significant fatigue symptoms. $^{15}$

There is a high prevalence of depression in persons with MS. ${ }^{16,17}$ The Mental Health Inventory-5 (MHI-5), a five-question subscale of the general health measure the SF-36 (Short Form Health Survey), ${ }^{18}$ was used to assess the mental health of participants. Scores range from 0 (worst mental health) to 100 (best mental health). Scores $\leq 76^{19}$ indicate common mental disorder and scores $\leq 52^{20}$ suggest severe depressive symptoms.

The Medical Doctor's Adverse Effect Report Form, designed and validated for this study, collected post-venoplasty follow-up by participating $\mathrm{BC}$ physicians. If the participant underwent multiple venoplasties, the very first one up to the most recent one at the time of the first initial Registry interview were reported on by the BC physicians.

The Registry was launched on 8 December 2011; the enrolment cutoff was 31 December 2013; the data collection cutoff was 31 July 2014.

\section{Statistical Analysis}

Descriptive statistics were employed to describe the demographics of our participants. Nonparametric analysis of longitudinal data in factorial experiments was used to analyse $\mathrm{e}^{21,22}$ Likert-type scale data over time on health conditions (14 questions), the frequency of exercise levels (3 questions) and rating the outcome of the venoplasty (1 question) collected at the initial and follow-up interviews. Bonferroni adjustment ${ }^{23}$ was applied to the level of significance for the 18 patient-reported outcomes; $p=0.0028(0.05 / 18)$ was considered significant. The one-way repeated-measures analysis of variance (RM ANOVA) ${ }^{24}$ was used (Mauchly's test was utilized to assess the assumption of sphericity) to analyse the MFIS-5 and MHI-5 scores over time, with significance being set at $p=0.05$.

\section{Results}

\section{Study Participants}

A total of 140 individuals were invited to participate in the study. Of these, $102(79.2 \%)$ completed the initial interview (74 females, 28 males, sex ratio=2.6), while 38 (26 females, 12 males, F:M sex ratio = 2.2) opted not to participate. There was no difference in sex ratio between participants and nonparticipants $\left(\chi^{2}=0.23, d f=1, p=0.63\right)$. Of the 102 participants, $93(91 \%)$ were re-interviewed at 6-month follow-up (FU), 83/93 (89\%) at 12 months and 55/83 (66\%) at 24 months (see Figure 1). 


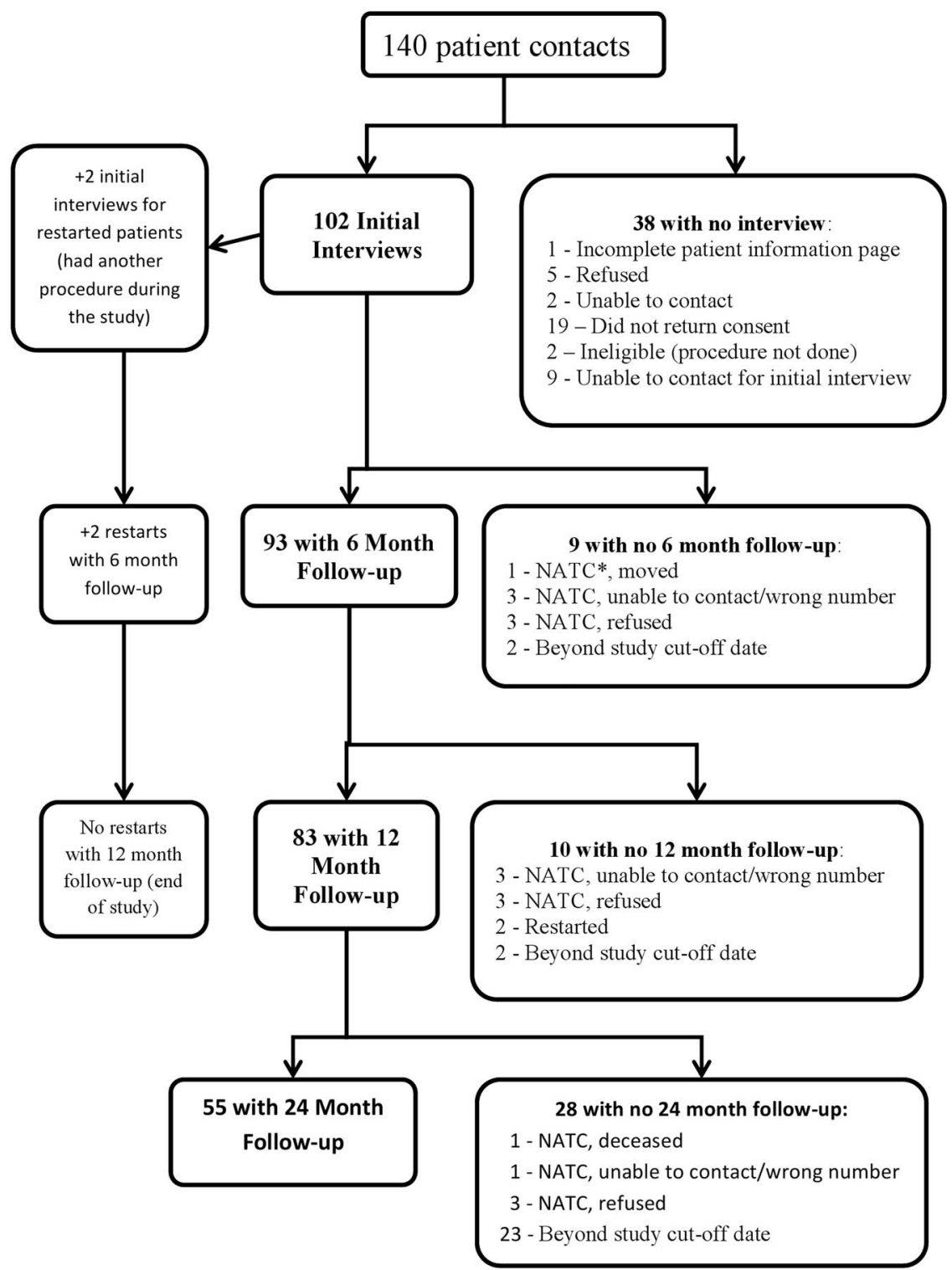

*NATC $=$ Not Able to Complete

Figure 1: Flowchart of data collection.

Some 65 of the 102 participants $(63.7 \%)$ reported relapsing remitting MS (RRMS) (Table 1). The average age at MS clinical onset was 31.9 years old $(S D=11.9)$, and the average age at MS diagnosis was $39.4(S D=12.7)$. The average age at the time of the first interview was 55.5 years old $(S D=10.8)$; and the "progressive MS" group (primary and secondary progressive MS cases combined) was significantly older than the "RRMS" group ( $t=2.8 ; d f=86 ; p=0.0064)$. The average elapsed time between the most recent venoplasty and the initial interview was 17.9 months $(S D=7.9)$. A total of 12 individuals $(11.8 \%$ : 9 females, 3 males) reported repeat venoplasty ( 8 had 2 procedures, 3 had 3 procedures and 1 had 4). The average elapsed time between repeat venoplasties was 10.7 months $(S D=8.8)$. Only 2 of the 102 participants (2\%) had a repeat venoplasty procedure within 6 months of the initial interview. Thus, data are reported for 102 MS patients who underwent a total of 104 venoplasties
( 89 balloon dilation only, 14 balloon dilation + stent, 1 unknown) during the study period.

Table 1: Participant-reported MS course before the venoplasty procedure and average age at the first "initial" interview

\begin{tabular}{l|c|c|c}
\hline MS course & $\boldsymbol{n}$ & Average age & $\boldsymbol{S D}$ \\
\hline Progressive $\mathrm{MS}^{1}$ & $23(22.5 \%)$ & 60.3 & 9.6 \\
\hline RRMS & $65(63.7 \%)$ & 53.0 & 11.0 \\
\hline Other $^{2}$ & $6(5.9 \%)$ & 61.2 & 11.5 \\
\hline Don't know & $8(7.9 \%)$ & 58.1 & 5.6 \\
\hline Overall & $\mathbf{1 0 2}$ & $\mathbf{5 5 . 5}$ & $\mathbf{1 0 . 8}$ \\
\hline
\end{tabular}

${ }^{1}$ Includes 13 primary and 10 secondary progressive MS cases.

${ }^{2}$ Includes 2 benign and 4 "other" MS cases. 
Table 2: Outcomes by participant-reported MS course at "initial”' interview

\begin{tabular}{|c|c|c|c|c|c|c|}
\hline & \multicolumn{3}{|c|}{$\operatorname{RRMS}\left(n=63^{\mathrm{a}}\right)$} & \multicolumn{3}{|c|}{ Progressive/other MS $\left(n=29^{b}\right)$} \\
\hline & Better $^{\mathrm{c}}$ & Same & Worse $^{\mathrm{d}}$ & Better $^{c}$ & Same & Worse $^{d}$ \\
\hline Participant-reported outcomes & $n(\%)$ & $n(\%)$ & $n(\%)$ & $n(\%)$ & $n(\%)$ & $n(\%)$ \\
\hline General health & $36(57.1)$ & $16(25.4)$ & $11(17.5)$ & $14(48.3)$ & $8(27.6)$ & $7(24.1)$ \\
\hline Fatigue level & $41(65.1)$ & $18(28.6)$ & $4(6.4)$ & $19(65.5)$ & $6(20.7)$ & $4(13.8)$ \\
\hline Pain & $20(31.7)$ & $41(65.1)$ & $2(3.2)$ & $8(27.6)$ & $19(65.5)$ & $2(6.9)$ \\
\hline Numbness & $26(41.2)$ & $34(54.0)$ & $3(4.8)$ & $11(37.9)$ & $15(51.7)$ & $3(10.3)$ \\
\hline Tingling & $23(36.5)$ & $39(61.9)$ & $1(1.6)$ & $10(34.5)$ & $15(51.7)$ & $4(13.8)$ \\
\hline Bladder control & $23(36.5)$ & $34(54.0)$ & $6(9.5)$ & $10(34.5)$ & $17(58.6)$ & $2(6.9)$ \\
\hline Bowel control & $14(22.2)$ & 47 (74.6) & $2(3.2)$ & $6(21.4)$ & $22^{\mathrm{e}}(78.6)$ & 0 \\
\hline Vision & $16(25.4)$ & $43(68.3)$ & $4(6.3)$ & $4(13.8)$ & $22(75.9)$ & $3(10.3)$ \\
\hline Balance & $33(52.4)$ & $25(39.7)$ & $5(7.9)$ & $12(41.4)$ & $10(34.5)$ & $7(24.1)$ \\
\hline Tremor & 15 (23.8) & $43(68.3)$ & $5(7.9)$ & $8(27.6)$ & 15 (51.7) & $6(20.7)$ \\
\hline Concentration & 25 (39.7) & $32(50.8)$ & $6(9.5)$ & $14(48.3)$ & $13(44.8)$ & $2(6.9)$ \\
\hline Mobility & $27(42.9)$ & $29(46.0)$ & $7(11.1)$ & $11(37.9)$ & $12(41.4)$ & $6(20.7)$ \\
\hline Exercise level & $29(46.0)$ & $24(38.1)$ & $10(15.9)$ & $19(65.5)$ & $4(13.8)$ & $6(20.7)$ \\
\hline
\end{tabular}

${ }^{\text {a } E x c l u d e s ~ t w o ~ R R M S ~ c a s e s ~ w h o ~ h a d ~ r e p e a t ~ v e n o p l a s t y ~ t h e r a p y ~ d u r i n g ~ t h e ~ s t u d y ~ p e r i o d . ~}$

bexcludes eight cases who "don't know" their MS course.

"Better: " $1=$ much better" plus " $2=$ somewhat better."

${ }^{\mathrm{d}}$ Worse: " $4=$ somewhat worse " plus " $5=$ much worse."

${ }^{\mathrm{e}}$ One participant refused to answer the question.

\section{Patient-Reported Outcomes (PROs)}

The results varied in terms of numbers and percentages per question, as participants were unable to answer all questions. At the initial interview, between 35 and $65 \%$ of patients reported improved outcomes (e.g., "much better $=1$ " and "somewhat better $=2$ " for a fatigue level of $65.2 \%$ (60/92) and tingling $35.9 \%$ (33/92)) (see Table 2 for details).

PROs at the initial interview (Supplemental Tables 1 to 3 show the frequency of exercise, level of stress in everyday life and rating of the outcome of the venoplasty, respectively). Selected summary results on the PROs for 83 participants followed up to 12 months post-venoplasty are presented in Tables 3 and 4. (The results on frequency of exercise are given in Supplemental Table 4). Table 5 shows the summary statistics of MFIS-5 and MHI-5 scores up to 12 months post-venoplasty.

The Likert-type scale showed a temporal decline in benefit from venoplasty for most PROs (see Figures 2 and 3 for the bar graphs of general health condition and fatigue level over the three interviews). Note that, for all outcomes, with the exception of rating the outcome of the venoplasty, higher scores indicate a worse outcome ("somewhat worse $=4$ " and "much worse $=5$ "). The results of the nonparametric analysis of the longitudinal data in the factorial experiment on patient self-reported data are presented in Table 6. After the Bonferroni adjustment, significant time effects were found for general health, fatigue level, mobility, sensory symptoms (pain, numbness and tingling), bladder/bowel control, vision, balance and concentration/memory. The relative treatment effects increased over time, indicating PROs with higher scores at the 6- and 12-month interviews compared to the initial interview. In contrast, no temporal changes were reported by PROs for tremor, exercise level and exercise frequency ("light," "moderate," "vigorous"), as well as the overall rating outcome of the venoplasty. This pattern persisted in the patientreported outcomes collected for up to 24 months. When the "progressive MS" and "RRMS" patient groups were examined separately, a similar temporal pattern of decline was shown for PROs.

A total of 77 of the 104 participants completing the initial interview $(74.0 \%)$ required some type of mobility assistance (cane, walker, wheelchair) prior to venoplasty, and 75/104 $(72.1 \%)$ reported this need after venoplasty $\left(\chi^{2}=0.098, d f=1\right.$, $p=0.75)$. Six patients who previously used mobility aids no longer required them post-venoplasty, but four newly required mobility aids after treatment. At 12 and 24 months, 65/83 (78\%) and $40 / 55(73 \%)$ reported requiring mobility assistance, respectively.

Of the 104 procedures with an initial interview, 101 completed the MFIS-5; 66/101 (65\%) scored >5; and 103 completed the MHI-5, of whom 48/103 (47\%) scored $\leq 76 ;{ }^{19}$ 14/103 scored $\leq 52,{ }^{20}$ suggestive of severe depressive symptoms. For all three interviews up to 12 months post-venoplasty, $79 / 83$ (95\%) participants completed the MFIS-5 and 81 (97.6\%) completed the MHI-5.

For the MFIS-5, Mauchly's test $(p=0.53)$ indicated that the assumption of sphericity was holding. The results of the RM ANOVA indicated that the MFIS-5 scores remained constant over time $(F=0.0611, p=0.94)$. The median MFIS-5 scores at the initial, 6- and 12-month interviews were 8,8 and 9, respectively. Thus, more than $50 \%$ of participants reported that fatigue impacted their daily activity. For the MHI-5, Mauchly's test $(p=0.64)$ indicated that the assumption of sphericity was holding. 
Table 3: Patient-reported outcomes relative to pre-treatment status up to the 12-month interview in percentage (\%)

\begin{tabular}{l|c|c|c|c|c|c|c|c|c|c}
\hline & & \multicolumn{3}{|c|}{ Initial interview } & \multicolumn{3}{|c}{ 6-month FU } & \multicolumn{2}{c}{ 12-month FU } \\
\hline Participant-reported outcomes & $\boldsymbol{n}^{\mathbf{a}}$ & Better $^{\mathbf{b}}$ & Same & Worse $^{\mathbf{c}}$ & Better $^{\mathbf{b}}$ & Same & Worse $^{\mathbf{c}}$ & Better $^{\mathbf{b}}$ & Same & Worse $^{\mathbf{c}}$ \\
\hline General health & 83 & 51.8 & 28.9 & 19.3 & 20.5 & 53.0 & 26.5 & 25.3 & 48.2 & 26.5 \\
\hline Fatigue level & 83 & 61.4 & 30.1 & 8.4 & 20.5 & 57.8 & 21.7 & 19.3 & 55.4 & 25.3 \\
\hline Pain & 82 & 25.6 & 72.0 & 2.4 & 9.8 & 70.7 & 19.5 & 14.6 & 69.5 & 15.9 \\
\hline Numbness & 82 & 32.9 & 59.8 & 7.3 & 13.4 & 67.1 & 19.5 & 11.0 & 64.6 & 24.4 \\
\hline Tingling & 82 & 31.7 & 62.2 & 6.1 & 9.8 & 69.5 & 20.7 & 8.5 & 73.2 & 18.3 \\
\hline Bladder control & 82 & 37.8 & 54.9 & 7.3 & 17.1 & 67.1 & 15.9 & 11.0 & 63.4 & 25.6 \\
\hline Bowel control & 81 & 25.9 & 71.6 & 2.5 & 6.2 & 86.4 & 7.4 & 9.9 & 81.5 & 8.6 \\
\hline Vision & 82 & 22.0 & 69.5 & 8.5 & 1.2 & 73.2 & 25.6 & 4.9 & 70.7 & 24.4 \\
\hline Balance & 82 & 42.7 & 45.1 & 12.2 & 9.8 & 50.0 & 40.2 & 13.4 & 57.3 & 29.3 \\
\hline Tremor & 82 & 23.2 & 67.1 & 9.8 & 7.3 & 75.6 & 17.1 & 11.0 & 74.4 & 14.6 \\
\hline Concentration & 82 & 40.2 & 52.4 & 7.3 & 4.9 & 74.4 & 20.7 & 4.9 & 87.8 & 7.3 \\
\hline Mobility & 82 & 36.6 & 50.0 & 13.4 & 12.2 & 53.7 & 34.1 & 15.9 & 50.0 & 34.1 \\
\hline Exercise level & 82 & 51.2 & 30.5 & 18.3 & 31.7 & 48.8 & 19.5 & 29.3 & 42.7 & 28.0 \\
\hline
\end{tabular}

${ }^{\mathrm{a}}$ On each specific condition, the case who did not report outcomes in all three interviews was excluded.

better: " $1=$ much better" plus " $2=$ somewhat better."

cWorse: "3 = somewhat worse" plus " 4 = much worse."

The result of the RM ANOVA indicated that MHI-5 scores also remained constant over time $(F=1.37, p=0.26)$. The median MHI-5 scores were 84 for the three different interviews. The average MHI-5 scores were $77.5 \quad(S D=17.1), 79.3$ $(S D=15.0)$ and $80.0(S D=15.1)$ at the initial, 6- and 12-month interviews, respectively. There were similar results when the MFIS-5 and MHI-5 scores were available at the 24-month follow-up.

\section{Physician-Reported Outcomes}

The Registry received physician-reported data forms for $72 / 102(70.6 \%)$ unique participants (a total of 80 report forms, including repeat venoplasties). Some 52 of the 80 reports $(65 \%)$ indicated new medication after venoplasty-anticoagulants $15 / 52$ (28.8\%); acetylsalicylic acid 16/52 (30.8\%); Plavix 18/52 $(34.6 \%)$; and other unspecified but not disease-modifying therapies $17 / 52(32.7 \%)$.

When examining the physician perceptions of the benefit from venoplasty, $9 / 80(11.3 \%)$ and 12/80 (15.0\%) reports indicated significant and modest benefits, respectively. However, no physician reported temporal improvement.

A total of 20 of the 80 reports $(25.0 \%)$ showed agreement between participant and physician perceptions of the benefit of venoplasty: $8(10.0 \%)$ "significant," $5(6.3 \%)$ "modest" and $7(8.8 \%)$ "none." Physicians perceived venoplasty as less beneficial than did patients in $33 / 80$ reports $(41.3 \%)$. The remaining $26 / 80(33.7 \%)$ reports had "unknown" in one or both of the patient's and physician's perceptions.

\section{Safety}

A total of 12 of the 104 venoplasties (11.5\%) resulted in complications during the procedure. In addition, 18/104 (17.3\%) complications were within the first month after the most recent venoplasty. Serious procedure-related complications included a tear in the azygos vein $(n=1)$, thrombosis $(n=1)$ and bursting of the balloon $(n=1)$. Other complications within the first month after venoplasty included thrombosis $(n=2)$, allergic reaction to blood thinner requiring hospitalization on return to Canada

Table 4: Rating the outcome of venoplasty therapy for participants who completed all interviews up to 12-month follow-up

\begin{tabular}{|c|c|c|c|c|c|c|}
\hline \multirow[b]{2}{*}{ Rating of procedure } & \multicolumn{2}{|c|}{ Initial interview } & \multicolumn{2}{|c|}{ 6-month FU } & \multicolumn{2}{|c|}{ 12-month FU } \\
\hline & $n$ & $\%$ & $n$ & $\%$ & $n$ & $\%$ \\
\hline $1=$ not at all helpful & 12 & $14.8 \%$ & 19 & $23.5 \%$ & 19 & $23.5 \%$ \\
\hline 2 & 13 & $16.0 \%$ & 11 & $13.6 \%$ & 12 & $14.8 \%$ \\
\hline 3 & 16 & $19.8 \%$ & 15 & $18.5 \%$ & 16 & $19.8 \%$ \\
\hline 4 & 12 & $14.8 \%$ & 15 & $18.5 \%$ & 14 & $17.3 \%$ \\
\hline $5=$ extremely helpful & 28 & $34.6 \%$ & 21 & $25.9 \%$ & 20 & $24.7 \%$ \\
\hline Total & $81^{\mathrm{a}}$ & $100.0 \%$ & 81 & $100.0 \%$ & 81 & $100.0 \%$ \\
\hline
\end{tabular}

${ }^{\text {a }}$ Two cases who did not report outcomes in all three interviews were excluded. 
Table 5: Summary of the scores on the Modified Fatigue Impact Scale-5 (MFIS-5) and on the Mental Health Inventory-5 (MHI-5)

\begin{tabular}{l|c|c|c|c|c|c}
\hline & \multicolumn{3}{|c|}{$\begin{array}{c}\text { Modified Fatigue Impact Scale-5 } \\
\text { (MFIS-5) }\end{array}$} & \multicolumn{3}{c}{ Mental Health Inventory-5 (MHI-5) } \\
\hline & Initial interview & 6-month FU & 12-month FU & Initial interview & 6-month FU & 12-month FU \\
\hline Number of participants with scores $^{\mathrm{a}}$ & 79 & 79 & 79 & 81 & 81 & 81 \\
\hline Average & 8.2 & 8.1 & 8.1 & 77.5 & 79.3 & 80.0 \\
\hline$S D$ & 5.6 & 5.6 & 5.0 & 17.1 & 15.0 & 15.1 \\
\hline $25 \%$ quantile & 3.5 & 3.0 & 4.0 & 68.0 & 76.0 & 72.0 \\
\hline $50 \%$ quantile & 8.0 & 8.0 & 9.0 & 84.0 & 84.0 & 84.0 \\
\hline $75 \%$ quantile & 12.0 & 13.5 & 12.0 & 88.0 & 88.0 & 88.0 \\
\hline
\end{tabular}

${ }^{\mathrm{a}}$ Known scores on all interviews.

$(n=1)$, bleeding and large haematoma in the right groin $(n=1)$, chest pain and depression $(n=1)$, stroke $(n=1)$, and arrhythmia $(n=1)$. Tables 7 and 8 list the complications by type of treatment (dilation only, stent and/or balloon) as reported by patients.

Two participants had a second venoplasty during the study period, and one of these bled and had a large haematoma in the right groin within the first month after the second procedure.

Physician-reported peri-procedure complications were indicated in 17 procedures, including azygos vein dissection $(n=1)$, menorrhagia $(n=1)$, bleeding and marked bruising $(n=1)$, hypertension requiring admission to the coronary care unit for monitoring $(n=1)$, pain $(n=1)$, inadequate sedation for procedure $(n=1)$ and unspecified $(n=11)$. A total of 20 procedures had complications within the first month after the procedure, including pain $(n=7)$, hypertension 3 to 4 hours post-operatively $(n=2)$, anaemia secondary to anticoagulation $(n=1)$, constipation but likely travel-related $(n=1)$, and unspecified $(n=10)$.

\section{Discussion}

This is the first longitudinal study looking at the "real-world" safety and sustained efficacy of venoplasty by systematically collecting PROs. Of the 13 symptom domains evaluated, $61.4 \%$ $(51 / 83)$ of patients reported improvement with respect to fatigue initially post-procedure. Up to $19.3 \%$ (16/83) reported a worsening in their general health condition (Table 3 ). However, on follow-up interviews, very few patients had sustained improvement after the initial interview at 6,12 or 24 months.

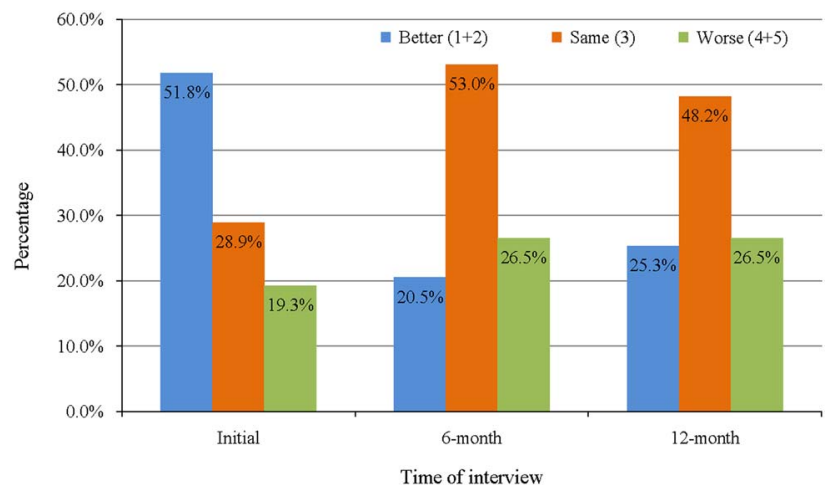

Figure 2: Patient-reported outcome of general health condition over time $(N=83)$.
Physicians reported significant or modest improvement in $26.3 \%$ of patients, but agreement between the perception of physicians and participants on venoplasty outcome with respect to MS could be found in only a quarter of the reports.

Some 84 of the 101 participants $(83.2 \%$; one did not provide information) who had venoplasty were managed at a BC MS clinic prior to treatment and subsequently returned to a BC MS clinic for ongoing care following the procedure, even though their medical tourism for venoplasty was against the advice of their MS physician.

Registry data indicated that undergoing venoplasty was not risk-free, with patients reporting adverse events, including major complications during $(12 / 104=11.5 \%)$ and within a month of the procedure $(18 / 104=17.3 \%)$. These complications included bleeding, hypertension, arrhythmia and stroke. It was beyond the scope of our study to inquire about supposed procedure-related complications later than a month postvenoplasty.

Our study is unique in terms of its longitudinal design and with patient-oriented standardized questionnaires administered to participants by trained interviewers, thus ensuring completeness and consistency of data as well as providing longitudinal changes in the health conditions of the patients following venoplasty. Importantly, as the patients self-reported their conditions posttreatment, there was no "physician impact" on longer-term outcomes. The availability of physician reports made comparison with patient reports possible; however, the physician reports were collected only once and not longitudinally.

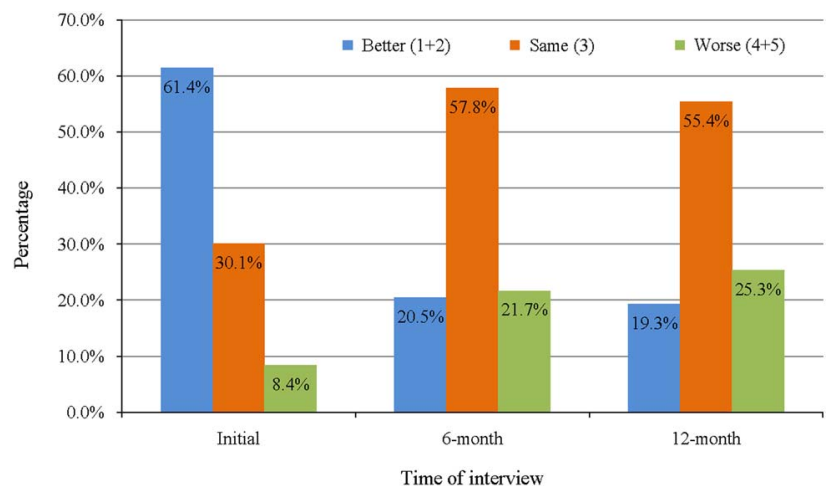

Figure 3: Patient-reported outcome of change in fatigue level over time $(N=83)$. 
Table 6: Results of the nonparametric analysis of longitudinal Likert-type scale data in factorial experiments

\begin{tabular}{|c|c|c|c|c|c|c|}
\hline \multirow[b]{2}{*}{ Participant-reported outcomes } & \multirow[b]{2}{*}{$n^{\mathbf{a}}$} & \multicolumn{3}{|c|}{ Relative treatment effect } & \multicolumn{2}{|c|}{ Wald-type statistic } \\
\hline & & Time 1: initial & Time 2: 6-month FU & Time 3: 12-month FU & Statistic. $(d f=2)$ & $p$ value $^{\mathrm{b}}$ \\
\hline General health & 83 & 0.40 & 0.56 & 0.54 & 19.87 & $4.86 \mathrm{e}-05^{*}$ \\
\hline Fatigue level & 83 & 0.34 & 0.57 & 0.58 & 48.54 & $2.88 \mathrm{e}-11 *$ \\
\hline Pain & 82 & 0.34 & 0.57 & 0.59 & 49.57 & $1.73 \mathrm{e}-11 *$ \\
\hline Numbness & 82 & 0.40 & 0.53 & 0.56 & 24.78 & $4.17 \mathrm{e}-06^{*}$ \\
\hline Tingling & 82 & 0.40 & 0.55 & 0.55 & 27.05 & $1.33 \mathrm{e}-06^{*}$ \\
\hline Bladder control & 82 & 0.40 & 0.52 & 0.58 & 23.33 & $8.60 \mathrm{e}-06^{*}$ \\
\hline Bowel control & 81 & 0.43 & 0.54 & 0.53 & 17.15 & $1.89 \mathrm{e}-4^{*}$ \\
\hline Vision & 82 & 0.40 & 0.56 & 0.54 & 27.08 & $1.32 \mathrm{e}-06^{*}$ \\
\hline Balance & 82 & 0.36 & 0.59 & 0.54 & 42.84 & $4.99 \mathrm{e}-10 *$ \\
\hline Tremor & 82 & 0.44 & 0.54 & 0.52 & 8.59 & 0.014 \\
\hline Concentration/memory & 82 & 0.37 & 0.59 & 0.53 & 38.93 & $3.53 \mathrm{e}-09^{*}$ \\
\hline Mobility & 82 & 0.39 & 0.56 & 0.55 & 27.47 & $1.08 \mathrm{e}-06^{*}$ \\
\hline Exercise level & 82 & 0.42 & 0.52 & 0.56 & 12.72 & 0.0017 \\
\hline Light exercise: frequency & 81 & 0.51 & 0.50 & 0.49 & 0.62 & 0.73 \\
\hline Moderate exercise: frequency & 81 & 0.48 & 0.48 & 0.54 & 8.57 & 0.014 \\
\hline Vigorous exercise: frequency & 81 & 0.49 & 0.51 & 0.50 & 0.83 & 0.66 \\
\hline Stress level & 82 & 0.51 & 0.50 & 0.49 & 0.26 & 0.88 \\
\hline Rating of outcome of therapy & 81 & 0.54 & 0.49 & 0.48 & 9.27 & 0.0097 \\
\hline
\end{tabular}

${ }^{\mathrm{a} O n}$ each specific condition, the participant who did not report outcomes in all three interviews was excluded.

${ }^{\mathrm{b}}$ The Bonferroni adjustment was applied to the level of significance for 18 comparisons, and $p=0.05 / 18=0.0028$ was considered the level of significance. ${ }^{*} p$ value $<0.0028$.

The study did have its limitations. Participation in the BC CCSVI Registry was voluntary and so did not represent a random or population-based sampling, thus resulting in possible self-selection

\section{Table 7: Participant self-reported procedure-related complications}

\begin{tabular}{|c|c|c|}
\hline $\begin{array}{l}\text { Study } \\
\text { ID }\end{array}$ & $\begin{array}{l}\text { Treatment } \\
\text { type }\end{array}$ & Complications \\
\hline 1220 & $\mathrm{D}$ & $\begin{array}{l}\text { Unable to finish treatment because one of the arteries to the } \\
\text { brain was } 90 \% \text { blocked; pain }\end{array}$ \\
\hline 1258 & $\mathrm{D}$ & $\begin{array}{l}\text { Not given enough anaesthetic, woke up during the } \\
\text { procedure }\end{array}$ \\
\hline 1217 & & $\begin{array}{l}\text { Unable to get the balloon through the leg, so went in } \\
\text { through the neck with a second incision }\end{array}$ \\
\hline 1236 & $\mathrm{D}$ & Pain \\
\hline 1245 & $\mathrm{D}$ & Tear in azygos vein; bleeding; pain \\
\hline 1299 & $\mathrm{D}$ & Pain \\
\hline 1125 & $\mathrm{D}$ & Pain \\
\hline 1126 & $\mathrm{D}$ & Pain \\
\hline 1101 & $\mathrm{D}$ & Panic attack \\
\hline 1166 & $\mathrm{D}$ & One of the balloons burst (opened seven veins); pain \\
\hline 1138 & $\mathrm{D}$ & Pain \\
\hline 1292 & $\mathrm{~S}$ & $\begin{array}{l}\text { Thrombosis developing during initial procedure, repeated } \\
\text { again the next day }\end{array}$ \\
\hline
\end{tabular}

Patient-reported treatment: $\mathrm{D}=$ dilation only; $\mathrm{S}=$ stent. bias. However, the data show a good balance of PROs in terms of improvement and no improvement at the initial interview. Another limitation was the lack of standardization in terms of diagnosis and treatment at the various centres where the procedures were performed.

When examining MFIS-5 scores, more than $50 \%$ of patients (median MFIS-5 score $\geq 8$ ) had fatigue symptoms. This rate remained constant over time (see Table 5), which suggested that the venoplasty was not effective in improving fatigue. When looking at MHI-5 scores, $47 \%$ of patients entering the study had an MHI-5 score $\leq 76,{ }^{19}$ suggesting that they had some mental disorder. In particular, $14 \%$ had severe depressive symptoms $(\mathrm{MHI}-5$ score $\leq 52) .^{20}$ Depression is associated with increased morbidity and mortality, and is regarded by MS patients as one of the main determinants of their quality of life. ${ }^{16}$

While patients perceived that the venoplasty had positive effects on such health conditions as fatigue, balance, vision and concentration/memory, this improvement was generally noted at the initial interview and declined over time (Table 3). If this represents, at least in part, a treatment benefit, the concern is that it does not appear to be sustained. Given the invasive nature of the therapy and the risk with stents, regular repeat therapy is not feasible in an attempt to maintain the perceived benefit seen post-treatment.

Thus, in conclusion, patient and/or physician perceptions of the positive impact of venoplasty on the health conditions of MS patients was not sustained over time. A sham controlled and blinded clinical trial is underway at four Canadian MS centres to assess the efficacy, safety and durability of balloon venoplasty for the treatment of extracranial venous narrowing in patients with MS. 
Table 8: Participant self-reported complications within the first month after the procedure

\begin{tabular}{|c|c|c|}
\hline $\begin{array}{l}\text { Study } \\
\text { ID }\end{array}$ & $\begin{array}{l}\text { Treatment } \\
\text { type }\end{array}$ & Complications \\
\hline 1220 & $\mathrm{D}$ & Within the first week after treatment, there were three occasions of heart attack symptoms \\
\hline 1258 & $\mathrm{D}$ & The incision had not been stitched up properly; the case, who is a first aid attendant, had to close the wound himself \\
\hline 1269 & $\mathrm{D}$ & Had a hard time breathing \\
\hline 1239 & $\mathrm{D}$ & There was swelling in the left arm; need to use blood-thinner drug \\
\hline 1274 & $\mathrm{D}$ & $\begin{array}{l}\text { Three days after felt weak, pressure on chest, pale and sweating; taken to CCU and treated with aspirin; told it was a vasovagal reaction (arrhythmia); } \\
\text { monitored for } 12 \text { hours and released; given anticoagulants for } 10 \text { days; continued to feel ill for another month }\end{array}$ \\
\hline 1205 & $\mathrm{D}$ & Bruising from anticoagulant injections \\
\hline 1273 & $\mathrm{D}$ & $\begin{array}{l}\text { "Couldn't move"; nothing functioned as well; allergic reaction to blood thinners, caused big blisters on heels and back of legs; hospitalized upon return to } \\
\text { Canada }\end{array}$ \\
\hline 1120 & $\mathrm{D}$ & Had back spasms and treated with Demerol \\
\hline 1237 & $\mathrm{D}$ & Bleeding; other: large haematoma in the right groin two hours later; felt like he was going to pass out; vagus nerve reaction \\
\hline 1284 & $\mathrm{D}$ & Thrombosis/blood clot \\
\hline 1122 & $\mathrm{D}$ & Bleeding \\
\hline 1123 & $\mathrm{D}$ & Severe chest pain and profound depression after procedure; pain \\
\hline 1134 & $\mathrm{D}$ & Pain \\
\hline 1243 & $\mathrm{~S}$ & Pain \\
\hline 1294 & $\mathrm{~S}$ & Stroke; onset of type 1 diabetes occurred same time as stroke; stroke could be diabetes- or CCSVI-procedure-related \\
\hline 1293 & $\mathrm{~S}$ & Pain \\
\hline 1292 & $\mathrm{~S}$ & Thrombosis/blood clot \\
\hline 1129 & $\mathrm{~S}$ & Pain \\
\hline
\end{tabular}

Patient-reported treatment: $\mathrm{D}=$ dilation only; $\mathrm{S}=$ stent.

\section{ACKNOWLEDGEMENTS AND FUNDING}

This study was funded by the British Columbia Ministry of Health. We are enormously grateful to the individuals who participated in the study. We also thank Madonna de Lemos and Talitha Greenwood for data collection, and Kevin Atkins for data management and extraction.

\section{Disclosures}

ADS has received grant funding from Biogen Idec, Teva Canada Innovation, Sanofi Genzyme and Novartis, and she has received partial travel funds for ECTRIMS 2016 from Roche.

IMY, GK and LK have no disclosures to report.

KAP has received consultancy meeting fees from Biogen Idec, is a principal investigator for Novartis and Biogen Idec, and has received fees for seeing study patients.

ALT has received research support from Sanofi Genzyme, Roche, Biogen Idec and Chugai Pharmaceutical, and has served as consultant/advisor for Sanofi Genzyme, Roche, Teva Canada Innovation and Biogen Idec.

\section{STATEMENT OF AUTHORSHIP}

ALT was principal investigator and ADS was co-principal investigator. The study was designed by ALT, ADS, IMY and KAP. GK and LK provided refinement to the study design. IMY wrote the first draft. All authors reviewed and provided input toward the final version, prepared by ADS and ALT. The data were reviewed and analysed by ALT, ADS and IMY. Statistical analysis was conducted by IMY. Literature searches were performed by IMY, ADS and ALT.

\section{SUPPLEMENTARY MATERIAL}

To view supplementary material for this article, please visit https:/doi.org/10.1017/cjn.2017.27

\section{REFERENCES}

1. Noseworthy JH, Lucchinetti C, Rodriguez M, Weinshenker BG. Multiple sclerosis. N Engl J Med. 2000;343(13):938-52.

2. Ebers GC. Environmental factors and multiple sclerosis. Lancet Neurol. 2008;7(3):268-77.

3. MS International Federation. Available at: http://www.msif.org/ about-us/advocacy/atlas-of-ms/.

4. Zamboni P, Galeotti R, Menegatti E, et al. Chronic cerebrospinal venous insufficiency in patients with multiple sclerosis. J Neurol Neurosurg Psychiatry. 2009;80(4):392-9; Epub ahead of print Dec 5, 2008. Available at: https://www.ncbi.nlm.nih.gov/pmc/ articles/PMC2647682/.

5. Zamboni P, Menegatti E, Weinstock-Guttman B, et al. Hypoperfusion of brain parenchyma is associated with the severity of chronic cerebrospinal venous insufficiency in patients with multiple sclerosis: a cross-sectional preliminary report. BMC Med. 2011;9:22. Available at: https://www.ncbi.nlm.nih.gov/pmc/ articles/PMC3059278/.

6. Zamboni P, Menegatti E, Galeotti R, et al. The value of cerebral Doppler venous haemodynamics in the assessment of multiple sclerosis. J Neurol Sci. 2009;282:21-7; Epub ahead of print Jan 13.

7. Zamboni P. The big idea: iron-dependent inflammation in venous disease and proposed parallels in multiple sclerosis. J R Soc Med. 2006;99(11):589-93; Available at: https://www.ncbi.nlm.nih.gov/ pmc/articles/PMC1633548/.

8. Zamboni P, Galeotti R, Menegatti E, et al. A prospective open-label study of endovascular treatment of chronic cerebrospinal venous insufficiency. J Vasc Surg. 2009;50(6):1348-58; Available at: http://www.jvascsurg.org/article/S0741-5214(09)01568-7/pdf. 
9. Tsivgoulis G, Faissner S, Voumvourakis K, et al. "Liberation treatment" for chronic cerebrospinal venous insufficiency in multiple sclerosis: the truth will set you free. Brain Behav. 2015;5(1):3-12; Epub ahead of print Nov 21, 2014. Available at: https://www. ncbi.nlm.nih.gov/pmc/articles/PMC4321389/.

10. Vera C, Herr A, Mandato K, Englander M, Ginsburg L, Siskin GP. Internet-based social networking and its role in the evolution of chronic cerebrospinal venous insufficiency. Tech Vasc Interv Radiol. 2012;15(2):153-7.

11. Oxford Reference. Oxford: Oxford University Press. Available at: http://www.oxfordreference.com/view/10.1093/oi/authority.20110 803100105644.

12. Ploughman M, Beaulieu S, Harris C, et al. The Canadian survey of health, lifestyle and ageing with multiple sclerosis: methodology and initial results. BMJ Open. 2014;4(7):e005718. Available at: https://www.ncbi.nlm.nih.gov/pmc/articles/PMC4120418/.

13. Kos D, Kerckhofs E, Nagels G, D'hooghe MB, Ilsbroukx S. Origin of fatigue in multiple sclerosis: review of the literature. Neurorehabil Neural Repair. 2008;22(1):91-100; Epub ahead of print Apr 4, 2007. Available at: http://journals.sagepub.com/doi/abs/ 10.1177/1545968306298934?url_ver=Z39.88-2003\&rfr_id=ori: rid:crossref.org\&rfr_dat $=$ cr_pub\%3dpubmed.

14. Fischer JS, LaRocca NG, Miller DM, Ritvo PG, Andrews H, Paty D. Recent developments in the assessment of quality of life in multiple sclerosis (MS). Mult Scler. 1999;5(4):251-9.

15. Sepulcre J, Masdeu JC, Goñi J, et al. Fatigue in multiple sclerosis is associated with the disruption of frontal and parietal pathways. Mult Scler. 2009;15(3):337-44; Epub ahead of print Nov 5, 2008. Available at: http://journals.sagepub.com/doi/abs/10.1177/1352 458508098373?url_ver=Z39.88-2003\&rfr_id=ori:rid:crossref. org\&rfr_dat $=$ cr_pub\%3dpubmed.

16. Feinstein A. Multiple sclerosis and depression. Mult Scler. 2011; 17(11):1276-81; Available at: http://journals.sagepub.com/doi/
abs/10.1177/1352458511417835?url_ver=Z39.88-2003\&rfr_id= ori:rid:crossref.org\&rfr_dat $=$ cr_pub\%3dpubmed.

17. Arnett PA, Barwick FH, Beeney JE. Depression in multiple sclerosis: review and theoretical proposal. J Int Neuropsychol Soc. 2008; 14(5):691-724; Available at: https://www.cambridge.org/core/ journals/journal-of-the-international-neuropsychological-society/ article/div-classtitledepression-in-multiple-sclerosis-review-andtheoretical-proposaldiv/139E9F9BD37CC5ECF5D3BD37AFB F937A/core-reader.

18. Ware JE Jr, Kosinski M, Bandek B. SF-36 Health Survey: Manual and Interpretation Guide, 2nd ed. Lincoln, RI: Quality Metric Incorporated; 2007.

19. Kelly MJ, Dunstan FD, Lloyd K, Fone DL. Evaluating cutpoints for the MHI-5 and MCS using the GHQ-12: a comparison of five different methods. BMC Psychiatry. 2008;8:10. Available at: https://www.ncbi.nlm.nih.gov/pmc/articles/PMC2265280/.

20. Bultmann U, Rugulies R, Lund T, Christensen KB, Labriola M, Burr H. Depressive symptoms and the risk of long-term sickness absence: a prospective study among 4747 employees in Denmark. Soc Psychiatry Psychiatr Epidemiol. 2006;41(11):875-80; Epub ahead of print Sep 1.

21. Brunner E, Munzel U, Puri ML. Rank score tests in factorial designs with repeated measures. J Multivar Anal. 1999;70:286-317.

22. Brunner E, Puri ML. Nonparametric methods in factorial designs. Stat Pap (Berlin). 2001;42(1):1-52.

23. Shaffer JP. Multiple hypothesis testing. Annu Rev Psych. 1995;46:561-84; Available at: http://wexler.free.fr/library/files/ shaffer\%20(1995)\%20multiple\%20hypothesis\%20testing.pdf.

24. Gueorguieva R, Krystal JH. Move Over ANOVA: progress in analyzing repeated-measures data and its reflection in papers published in the Archives of General Psychiatry. Arch Gen Psychiatry. 2004;61(3):310-7. 